\title{
Estrutura e organização do trabalho do cirurgião-dentista no PSF de municípios do Rio Grande do Norte
}

\author{
Structure and organization of the work of dentists \\ in the Family Health Program of some Municipal \\ Districts of Rio Grande do Norte (Brazil)
}

Yanne Pinheiro de Araújo 1

Magda Dimenstein 2

\footnotetext{
1 Secretaria Municipal de Saúde de Aracaju. Programa de PósGraduação em Odontologia, Departamento de Odontologia Preventiva, Faculdade de Odontologia, UFRN.

Av. Sen. Salgado Filho 1787, Lagoa Nova, 59.056-000, Natal RN. yanne.pinheiro@aracaju. se.gov.br

2 Programa de PósGraduação em Psicologia da UFRN.
}

Abstract The purpose of this research was to analyze the working profile of dentists from the Family Health Program of some Municipal Districts of Rio Grande do Norte (Brazil) in order to understand the way they handle the experience acquired with the work developed in that Program. The target population was composed of dentists from the FHP of Rio Grande do Norte. Thus we performed 21 interviews orientated by a semi-structured guidebook with open questions and identification data, beyond recording the speech of all the professionals. The main results found were: predominance in the female gender; the majority of dentists has no post graduation courses; in those few cases of dentists with some post-graduation a lack of correlation with Public or Collective Health was observed; the dentists interviewed present a profile directed to clinical activities; the dentists used to develop basic conducts and educative and preventive activities, even though the last two ones are carried out in an extremely traditional way (lectures and topical application of fluoride). The results indicate the existence of a necessity to lead them to reflect and redirect their practices. In order to reach this aim it must be considered as initial measure the investment and encouragement toward to permanent education as well as a close follow-up and evaluation of the actions developed by them.

Key words Insertion, FHP, Professional formation
Resumo Esta investigação tem como objetivo analisar o perfil de atuação de cirurgiões-dentistas inseridos no Programa de Saúde da Família (PSF) de municípios do Rio Grande do Norte, buscando conhecer e compreender a experiência de trabalho que estes profissionais desenvolvem no Programa. A população integrante da pesquisa foi composta de cirurgióes-dentistas PSF do Rio Grande do Norte. Foram realizadas 21 entrevistas orientadas por um roteiro semi-estruturado, com perguntas abertas e composta de dados de identificação. Optou-se por gravar a fala dos profissionais, tendo em vista uma melhor fidelidade da coleta de informações. Os principais resultados encontrados foram: predominância do sexo feminino; maioria dos entrevistados sem pós-graduação, verificando-se, entre seus portadores, a falta de relação entre o referido curso e a saúde pública ou coletiva; os cirurgiões-dentistas têm perfil voltado para a atividade clínica; estes profissionais desenvolviam atividades básicas de dentística, periodontia básica, cirurgia simples e atividades preventivas e educativas, embora realizadas de maneira tradicional (palestras e aplicação de flúor). Os resultados apontam que há necessidade de motivá-los a refletir e redirecionar as suas práticas, tendo como medida inicial o investimento e estímulo à educação permanente e um monitoramento e avaliação das ações desenvolvidas. Palavras-chave Inserção, PSF, Formação profissional 


\section{Introdução}

Tendo em vista a redução da disparidade existente entre os direitos sociais garantidos em lei e a capacidade concreta de oferta de ações de serviços públicos à população brasileira, foram definidas, a partir da promulgação da Constituição Federal de 1988, as diretrizes do Sistema Único de Saúde (SUS) brasileiro: a universalização, a eqüidade, a integralidade, a descentralização e a participação da comunidade.

Durante anos, foram estabelecidos vários modelos de atenção à saúde no país e o SUS sofreu inegáveis transformações. Em 1994, o Ministério da Saúde institucionalizou o Programa de Saúde da Família (PSF), com o objetivo de reorientar o modelo assistencial vigente, revertendo a forma da prestação de assistência à saúde que organizava a atenção básica. Porém, o cirurgião-dentista ainda não estava inserido nessa nova proposta.

Em 2000, foi criado o incentivo de saúde bucal pelo Ministério da Saúde, que propiciou a inserção das Equipes de Saúde Bucal (ESB) na estratégia Saúde da Família. Com este acontecimento, a integralidade dos cuidados, passo importante na observância dos princípios do SUS, pôde ser praticada.

Souza et al. 1 conceituam o PSF como uma estratégia para a reorganização da Atenção Básica que busca a vigilância à saúde por meio de um conjunto de ações individuais e coletivas, situadas no primeiro nível de atenção e voltadas para a promoção, prevenção e tratamento dos agravos à saúde. Referem que este programa, criado pelo Ministério da Saúde, pretende reorientar o modelo assistencial a partir da Atenção Básica, imprimindo uma nova dinâmica para a consolidação do SUS.

Este programa se constitui atualmente numa fonte de emprego em expansão para o cirurgião-dentista no Brasil. Entretanto, o cirurgião-dentista que trabalha no PSF vê-se freqüentemente diante de muitos desafios, sentindo-se, em alguns momentos, inseguro e despreparado para exercer as suas atividades. Isso porque ele recebeu uma educação voltada para as questões biológicas, ações curativas e técnicas, com pouca ênfase para os fatores socioeconômicos e psicológicos no processo saúdedoença e para o desenvolvimento de atividades de promoção, manutenção e recuperação da saúde.

Dentre as atividades exercidas pelos dentistas no PSF estão as ações preventivas e educati- vas. Estes, independentemente do tempo de formados, na maioria das vezes não estão preparados para essas atividades, realizando-as de maneira inadequada. A população reage imediatamente, ávida pelo tratamento curativo, resistindo a cada palestra, a cada reunião.

Observa-se atualmente, tanto no Rio Grande do Norte quanto nos demais estados brasileiros, uma expansão das ESBs no PSF. No entanto, a inclusão do dentista em alguns municípios está se dando de maneira desorganizada, sem planejamento por parte da gestão, o que acarreta apenas um acréscimo de horas de atendimento e aumento do número de pacientes e procedimentos. Procedimentos esses centrados na resolução imediata dos problemas de saúde bucal, atendendo apenas à demanda espontânea, sem a preocupação de realizar o tratamento do usuário por completo. Dessa forma, não há uma real melhoria das condições de saúde bucal da população.

Neste contexto, esta pesquisa objetivou analisar o perfil de atuação de cirurgiões-dentistas inseridos no PSF de municípios do Rio Grande do Norte, buscando conhecer e compreender sua experiência de trabalho desenvolvido no PSF. Essa compreensão é necessária para que haja uma avaliação e elaboração de estratégias no sentido de melhorar sua qualificação e suas condições de trabalho. Tal discussão envolve uma reflexão a respeito das perspectivas da consolidação deste programa e dos avanços possíveis do Sistema Único de Saúde no país.

\section{Revisão de literatura}

Contextualizando o leitor no campo de estudo deste trabalho, o Rio Grande do Norte, segundo dados do $\mathrm{IBGE}^{2}$, possui uma população de 2.923.287 habitantes, distribuídos em $167 \mathrm{mu}$ nicípios. E, de acordo com dados do Ministério da Saúde 3, em 2003, época de início do desenvolvimento desta pesquisa, 1.660 .517 pessoas eram assistidas pelo PSF, o que corresponde a aproximadamente $58 \%$ da população. Dentre as 6.170 equipes de saúde bucal no Brasil, 314 funcionavam no Rio Grande do Norte, distribuídas em 137 municípios e dispostas em 8 Unidades Regionais de Saúde Pública (Ursaps).

Segundo informações da Secretaria Estadual de Saúde do Rio Grande do Norte4, a implantação das ESBs no PSF do Rio Grande do Norte ocorreu em janeiro/fevereiro de 2001, e 
até janeiro de 2005 já haviam sido implantadas 475 Equipes de Saúde Bucal no RN.

A seleção dos profissionais para integrar as equipes do PSF realizou-se, em sua maioria, sem processo seletivo, fato comprovado na pesquisa organizada por Souza ${ }^{5}$, com 25 dentistas do PSF do Rio Grande do Norte. O estudo aponta a precarização das relações de trabalho, evidenciada pelas formas informais de vinculação e de contratação desses profissionais, observando-se um grande número de dentistas mantendo uma relação com o município firmada por meio de contratos temporários e com seleção por indicação.

No momento em que as equipes de saúde bucal foram contratadas, os profissionais eram capacitados, durante uma semana, através do Pólo de Capacitação em Saúde da Família, em parceria com o Centro de Formação para os Serviços de Saúde do Rio Grande do Norte (Cefope), dispostos nas 6 Unidades Regionais de Saúde Pública (Ursaps) do Estado.

Os processos de avaliação do PSF passaram a ocorrer com mais freqüência a partir do final da década de 1990, pois não havia experiências suficientes para serem analisadas, devido a sua implantação muito recente. Além disso, havia deficiências dos sistemas de informações, ausência de metodologias e técnicas adequadas. Publicações dessa natureza começaram a surgir só recentemente na Odontologia. No entanto, estas se limitam a explorar questões relacionadas à melhoria do acesso da população ao tratamento odontológico (número de procedimentos clínicos e coletivos), ou mesmo ao grau de aceitabilidade da população ao PSF. Não há avaliações sobre como o odontólogo está vivendo essa nova oportunidade de emprego, na qual ele está inserido nessa atual perspectiva de atenção à saúde, direcionada à família. Esse é um ponto a ser discutido no decorrer deste estudo.

A inserção dos cirurgiões-dentistas no Programa Saúde da Família, censura Werneck6 ${ }^{6}$, não se deu a partir de experiências já existentes ou de uma discussão ampliada acerca de seus significados. Aconteceu sem a participação dos profissionais de saúde bucal e de outros profissionais da área de saúde. Não houve discussão sobre a maneira como esses profissionais deveriam atuar na atenção básica, nem sobre as dificuldades que enfrentariam ao trabalhar com uma equipe de saúde. Conseqüentemente, haverá probabilidade de esses profissionais não estarem qualificados para desenvolver suas funções ou, ainda, que continuem trabalhando tra- dicionalmente, não contribuindo para melhorar as condições de saúde bucal da população.

Os procedimentos clínicos que fazem parte do elenco de atos da produção de saúde bucal da atenção básica, preconizadas pelo Ministério da Saúde7, e que o CD deverá executar são, basicamente, restaurações, periodontia básica, extrações, profilaxia e aplicação tópica de flúor em consultório.

A educação para a saúde também faz parte dos programas de saúde pública. Na prática, no entanto, tem-se observado que os profissionais envolvidos nos programas apresentam dúvidas de como e o que fazer. Muitas vezes atuam apenas como intermediários de informações e de materiais educativos produzidos por órgãos oficiais, nem sempre observando a realidade local. Portanto, apesar do esforço realizado, não se consegue obter o impacto esperado e os usuários dos serviços de saúde acabam recebendo a culpa pela sua incapacidade de compreender o que foi ensinado (Ministério da Saúde 8 ).

A educação em saúde tem sido praticada pelas ESBs, porém sempre foi abordada de maneira tradicional, sem a participação da comunidade nesse processo. Conforme essa idéia, Manfredini ${ }^{9}$ expressa que as ações educativas realizadas pelos cirurgiões-dentistas se restringem, na maioria das vezes, a palestras ou vídeos educativos. Cita ainda que, nas escolas, os temas de saúde bucal são pouco explorados pelos professores e que não há uma articulação entre as equipes de saúde bucal e estas instituições sobre a discussão ampliada e problematização destes temas.

Os métodos preventivos tradicionais estão ancorados em percepções do modo de aprender baseado na memorização de informações, o que não satisfaz o objetivo maior, que é a transformação do conhecimento em algo com revelação expressiva, capaz de efetivar-se em geração de autonomia dos próprios cuidados com a saúde.

Sabe-se da importância da educação para o controle das doenças bucais e, para isso, é necessária uma integração e articulação do setor saúde com o setor educação. Todavia, atualmente, não existe uma normatização das estratégias preventivas para a Odontologia. Para que a educação em saúde se torne efetiva, é preciso que não só os profissionais que lidam com a odontologia participem desse processo. É fundamental o relacionamento com os demais integrantes, como o médico e o enfermeiro. $\mathrm{O}$ 
dentista, através de reuniões de equipe, pode passar informações de saúde bucal para estes profissionais, que as irão repassar a seus pacientes.

No estudo de Moimaz citado por Pauleto, Pereira e Cyrino10, os autores avaliaram a utilização dos métodos de prevenção e educação em saúde bucal por cirurgiões-dentistas dos serviços públicos e particulares. A análise desse estudo, realizado a partir de questionários aplicados aos profissionais, permitiu concluir que, apesar da utilização de medidas preventivas por grande parte dos profissionais entrevistados, na prática de atendimento ao paciente, a educação odontológica não estava sendo realizada de maneira sistemática em ambos os serviços avaliados. Apesar de grande parte dos profissionais ter respondido que orientava os pacientes, os autores verificaram que aproximadamente a metade dos profissionais do serviço público e particular destinava apenas uma breve sessão para este fim, com duração máxima entre 20 e 25 minutos, tempo considerado insuficiente para uma comunicação efetiva, com possibilidades de aprendizagem e construção de conhecimentos novos.

Na esfera do PSF, a educação em saúde figura como uma prática prevista e atribuída a todos os profissionais que compõem a ESF. Espera-se que esta seja capacitada para assistência integral e contínua às famílias da área adscrita, identificando situações de risco à saúde na comunidade assistida para enfrentar, em parceria com a comunidade, os determinantes do processo saúde-doença, e desenvolver processos educativos para a saúde, voltados à melhoria do autocuidado dos indivíduos (Alves ${ }^{11}$ ).

Os profissionais do serviço deveriam atuar sob uma concepção mais ampla, em que trabalhar a doença não seja a prioridade e em que a promoção de saúde e prevenção da doença proporcionem às comunidades ferramentas $\mathrm{e}$ tecnologias para a sua participação no autocuidado (Viáfara \& Brugés ${ }^{12}$ ).

\section{Metodologia}

A população que integrou a pesquisa foi composta de cirurgiões-dentistas que estavam trabalhando no Programa de Saúde da Família (PSF) no Estado do Rio Grande do Norte. Foram realizadas 21 entrevistas com um roteiro semi-estruturado com perguntas abertas, para induzir o mínimo possível as respostas e recolher o maior número possível de percepções, captando a visão própria dos indivíduos. Foram colhidos também dados de identificação. Optouse por gravar a fala dos profissionais, tendo em vista uma melhor fidelidade da coleta de informações.

Inicialmente, foi realizado um estudo piloto, sorteando-se três dentistas que estão trabalhando no PSF de Natal, tendo em vista a necessidade da avaliação da adequação do instrumento de pesquisa. As entrevistas foram realizadas no mês de março de 2004, gravadas e aplicadas por um mesmo pesquisador. A seleção desses profissionais foi feita a partir de uma listagem fornecida pela Secretaria Estadual de Saúde do Rio Grande do Norte, que continha uma relação dos cirurgiões-dentistas inseridos nas Equipes de Saúde Bucal do PSF no Rio Grande do Norte de seis Unidades Regionais de Saúde Pública (Ursaps) do Estado, no período da pesquisa.

Foram escolhidos então os municípios indicados, nos quais está assinalado o número de dentistas correspondente: Touros (3), Nova Cruz (5), Governador Dix-Sept Rosado (3), Acari (3), Santa Cruz (3) e Pau dos Ferros (4), perfazendo um total de 21 cirurgiões-dentistas participantes. Cada município foi escolhido por ser o mais representativo da sua respectiva regional (Ursap), em termos de quantidade de equipes de saúde bucal implantadas no período do desenvolvimento da pesquisa.

$\mathrm{Na}$ pesquisa qualitativa, delineada por $\mathrm{Mi}$ nayo ${ }^{13}$, é o agrupamento de circunstâncias que dá sentido ao fato, e não uma situação isolada, oferecendo liberdade para resgatar o importante na novidade dos temas, mesmo se a freqüência é pequena. Triviños 14 menciona que o estudo qualitativo permite abordar pontos mais explicativos de uma situação e, com seus achados, posteriormente, pode-se realizar uma pesquisa extensiva que permita validar seus dados e apreciar sua variação segundo critérios pertinentes.

Os dados relativos à caracterização dos entrevistados foram analisados através de estatística descritiva, com representação em números absolutos. Essas informações estão classificadas em: idade, sexo, tempo de formado, município de atuação, tempo de inserção no PSF e pósgraduação. Os dados relativos às ações desenvolvidas no PSF foram analisados por agrupamento das categorias mais freqüentes, de acordo com as falas. Escolheram-se também as falas mais representativas para serem discutidas. 
Este estudo, que se enquadra na modalidade de pesquisa de risco mínimo, seguiu as normas e diretrizes da Resolução no 196/96 do Conselho Nacional de Saúde, Ministério da Saúde 15 e recebeu parecer favorável do Comitê de Ética e Pesquisa da UFRN. Para a sua realização, cada entrevistado assinou o termo de consentimento em participar da pesquisa.

\section{Resultados e discussões}

\section{Caracterização dos participantes}

A faixa etária predominante entre os entrevistados estava acima de 40 anos (11 CDs). Apenas 4 CDs tinham menos de 25 anos. No Brasil, segundo estudo realizado pelo Instituto Brasileiro de Estudos e Pesquisas Socioeconômicas - Inbrape16, em 2003, encontrou-se que $29,5 \%$ dos dentistas tinham de 26 a 35 anos. Nota-se que a faixa etária dos dentistas no PSF do Rio Grande do Norte, nos municípios pesquisados, é bem maior que a média brasileira. Isso se explica pelo fato de esses profissionais que trabalham no PSF terem sido "aproveitados”, isto é, já estavam trabalhando no município no momento em que implantaram as equipes.

Quanto ao sexo, encontrou-se maioria do sexo feminino (11 CDs), corroborando com um estudo elaborado pelo Inbrape ${ }^{16}$, realizado em 2003, no qual se encontrou que $57,5 \%$ dos dentistas no Brasil eram do sexo feminino. E ainda por meio de pesquisa realizada no Rio Grande do Norte em 2001, por Rodrigues17, visando conhecer o Perfil dos Profissionais de Saúde Bucal do Estado Rio Grande do Norte, em que se verificou que o percentual dos CDs do sexo feminino que trabalhavam no serviço público no Estado do RN era de 54,8\%.

O tempo de formado foi dividido em seis períodos: até 5 anos; de 6 a 10 anos; de 11 a 15 anos; de 16 a 20 anos; de 21 a 25 anos; e de 26 a 30 anos. Houve uma maior predominância do tempo de formado do período de até 5 anos (10 CDs). São os dentistas que se formaram há pouco tempo e que têm o PSF como opção de emprego. Esse dado tem fundamental importância na análise das respostas, pois nos permite entender a influência desse fator em diversas questões da vivência daqueles profissionais no PSF.

Quanto ao tempo de inserção no PSF, notou-se que a maioria dos CDs tem de 2 a 3 anos de trabalho no programa, correspondendo ao período de implantação das ESB no PSF no Rio Grande do Norte. Na Avaliação Normativa do Programa de Saúde da Família no Brasil através do monitoramento da implantação e funcionamento das equipes de saúde da família no período de 2001 a 2002 (Ministério da Saúde18), dois anos antes da realização deste estudo, notou-se que, no Rio Grande do Norte, 50\% dos dentistas estavam trabalhando de 7 a 12 meses e $49,3 \%$ por até 6 meses. Isso se deve ao fato de as ESBs só terem sido implantadas no ano de 2001. O Ministério da Saúde 18 reportou que a inserção dos profissionais nas equipes de saúde era recente, pois a maioria dos profissionais das ESF estava trabalhando a menos de um ano, principalmente os CDs. O mesmo acrescentou que $O$ pequeno tempo de permanência das equipes pode se constituir em fator limitante para o trabalho, dificultando desde a qualificação dos profissionais, até o desempenho das ações, tendo em vista a necessidade de adesão e incorporação de novos valores e o exercício de novas práticas de saúde (Ministério da Saúde18).

Encontrou-se que onze entrevistados não possuíam pós-graduação, e dos que possuíam, 4 eram pós-graduados em Prótese, 2 em Dentística, 2 em Periodontia, 2 em Endodontia e 2 em Cirurgia. $\mathrm{O}$ estudo de Rodrigues 17 apontou que $42,8 \%$ dos CDs que trabalhavam no serviço público do RN não tinham qualquer pósgraduação. Nota-se que há uma quantidade muito grande de cirurgiões-dentistas sem pósgraduação trabalhando no PSF, revelando uma quantidade maior até dos que trabalham no serviço público como um todo.

Dos CDs que atestaram não possuir pósgraduação (11 CDs), 9 têm de 16 a 20 anos de formatura, pois são de uma geração em que a concorrência na profissão não era tão intensa, havendo pouca procura por qualificação. $\mathrm{O}$ mercado de trabalho atual na Odontologia exige um profissional cada vez mais especializado para "vencer" a competição profissional.

\section{Estrutura e organização do trabalho dos cirurgiões-dentistas no PSF}

Deste momento em diante, dar-se-á início à análise das questões abertas, lembrando que estas foram gravadas e baseadas num roteiro de entrevista.

Os CDs foram questionados quanto ao tipo de ações que desenvolviam no PSF. No geral, a maioria respondeu que desenvolve atividades 
básicas: extrações, restaurações, periodontia básica, profilaxia; e também atividades preventivas e educativas: palestras, aplicação de flúor em crianças nas escolas, creches. Além de atendimento de urgência, visitas domiciliares e atendimento a hipertensos, diabéticos, gestantes e crianças.

As falas abaixo expressam essas respostas:

Bom, por enquanto a gente só tem atividades basicamente dentro do consultório, dada a procura, que é muito grande. Já entrei em contato com a Secretaria para ir nos colégios. [...] porque a gente vai começar a fazer palestra tanto nas escolas quanto na comunidade. Eu estou querendo destinar um turno pra fazer isso, mas mesmo assim estamos pretendendo começar essa parte de prevenção, mas vamos precisar de umas orientações (CD7).

Extração, curativo, restauração, profilaxia e flúor. [...] Tem resina foto. O material é bom. Eu trabalho nesse posto e em outro posto. [...] eu fico mais com a parte de restauração (CD21).

Bom, é como eu falei para você... nós trabalhamos a parte preventiva, né? Essa parte preventiva... ela consiste no seguinte: nós trabalhamos nas escolas, certo? De $3 \mathrm{em} 3$ meses nós fazemos um trabalho de palestras, orientação de escovação. Com a prevenção da cárie dentária, das doenças periodontais e do câncer bucal (CD6).

Eu sei que era para a gente desenvolver muitas atividades preventivas. Isso é o que mais se vê nos treinamentos do PSF, só que nós não fazemos isso. Eu não faço. Prevenção tipo palestra, ir numa escola fazer alguma orientação, não faço. No dia que se tira um horário de trabalho de procedimentos como exodontia, a população reclama. Teve uma época que a gente estava com falta de água no posto que a gente trabalhava, eu ia marcava atendimento com gestante para fazer orientação, e só foi uma. Tinha 50 gestantes na área, foi uma ou duas. Eles só vão se tiver alguma coisa em troca. Eles não vão pra obter informação. A gente sabe que o PSF tem tudo pra melhorar a saúde, tem tudo para dar certo. Só que a população não está educada pra esse método de trabalho. Ela não quer prevenção. Ela só quer mesmo tratamento curativo. A atividade que eu desenvolvo é exodontia. Atualmente tem pouco dentista fazendo restauração no município. Os dentistas do consultório particular é que devem estar gostando. Mas a população é altamente pobre. A cidade é grande, 40 e poucos mil habitantes, mas é pobre. A maioria trabalha na prefeitura ou trabalha numa fábrica de sandálias É um desestímulo fazer exodontia. Você está numa era da im- plantodontia, e a gente ainda tem que fazer extração. As pessoas não querem fazer restauração. Eles acham que se faz a restauração, no futuro vão ter que extrair. E se no futuro tiver que extrair e não tiver dentista? (CD17).

Infelizmente, o que constatamos nas seguintes falas é que os dentistas não estão fazendo atividades preventivas como deveriam ser realizadas. Relatam a dificuldade de praticá-las na comunidade e que a população exige o tratamento curativo. Alguns expressam a falta de material para o dentista realizar educação em saúde, ou que não sabem como realizá-la. Porém, esses fatores não justificam a ausência destas ações, pois há facilidade no acesso aos manuais de orientação do Ministério da Saúde, às faculdades de Odontologia, além de diversas maneiras de construir esses instrumentos educativos, inclusive com a participação da comunidade.

O Ministério da Saúde 18 analisa que no RN $30,9 \%$ das ESBs referiram possuir material suficiente para a realização de ações educativas, estando abaixo da média no Brasil que foi de $41,9 \%$. Considerando que o cirurgião-dentista dispõe de 40 horas semanais, é possível reservar um horário específico para este participar das atualizações da equipe, como capacitar os THDs, ACDs, ACSs e auxiliares de enfermagem. Assim, o CD deve ser um participante ativo das ações de promoção, educação e prevenção, dispondo de tempo para reunir-se com a equipe de saúde e com a população da área onde atua, participando dos processos de planejamento e avaliação das ações em desenvolvimento na sua região e no município como um todo, fazendo visitas aos domicílios, sempre que isso for necessário para conhecer profundamente a população e suas condições de vida (Capistrano Filho19).

Na verdade, a dificuldade de como trabalhar no PSF, relatada pelos CDs, é reflexo do modelo de saúde ainda vigente, o cirúrgicomutilador, no qual a quantidade de procedimentos predomina na mentalidade dos CDs e dos gestores.

Observa-se também que enquanto em alguns locais são realizadas restaurações fotopolimerizáveis, em outros só há exodontia, caracterizando a falta de planejamento e organização na utilização dos recursos provenientes do Ministério da Saúde.

Há ainda a falta de interesse por parte de alguns profissionais em realizar alguns procedimentos, como se observa pelo relato a seguir: Faço o básico, restaurações, extrações, raio $X$. $O$ 
aparelho de raio X é uma polêmica. Trabalhou durante um tempo, depois parou... aí não revela mais e eu não sei o que é (CD19).

Notou-se que à medida que os profissionais iam respondendo às questões, os relatos direcionavam ao não-cumprimento da carga horária semanal de 40 horas, que é exigida pelo $\mathrm{Mi}$ nistério da Saúde 7 . O que aparece nos relatos é que nenhum profissional cumpre essa carga horária, realizando, na maioria das vezes, quatro dias de trabalho e, em alguns casos, apenas um turno diário de atendimento. O fato também foi notado na pesquisa de Souza ${ }^{20}$.

Segundo o Ministério da Saúde ${ }^{18}$, o estabelecimento da carga horária de 40 horas para os profissionais das equipes de saúde sustenta-se na idéia de que esta é uma condição necessária para a criação de vínculos entre os membros da equipe e entre estes e a população. E, ainda, para melhor desenvolvimento do processo de trabalho das equipes, tanto do ponto de vista gerencial e organizacional, quanto assistencial. Em pesquisa realizada pelo próprio Ministério da Saúde, constatou-se que no Brasil, no período de 2001 a 2002, somente $68,3 \%$ dos cirurgiões-dentistas do PSF cumpriam a carga horária de 40 horas semanais. No $\mathrm{RN}$, apenas $48,7 \%$ a cumprem. Situação melhor do que a dos médicos $(41,7 \%)$ e pior do que a dos enfermeiros $(50,5 \%)$. Esse fato ressalta a necessidade de uma maior fiscalização quanto à efetividade dessa carga horária.

Uma atividade de grande importância no âmbito da educação e prevenção é a visita domiciliar, que possibilita o conhecimento da situação de saúde das famílias com uma maior profundidade; o desenvolvimento de ações promocionais; o acompanhamento de grupos. Além disso, constitui-se em forte elemento no estabelecimento de vínculos entre as equipes e as famílias (Ministério da Saúde18). Segundo os relatos, porém, esta é uma atividade pouco executada por esses profissionais, e quando o é, não há priorização da visita de acordo com o risco das famílias a serem visitadas.

A incorporação do atendimento domiciliar aponta para uma reestruturação e reorganização das práticas de saúde para além dos muros dos serviços de saúde, deslocando seu olhar para o espaço domicílio das famílias e comunidades nas quais as práticas estão enraizadas (Trad \& Bastos 21$)$.

A maioria dos entrevistados referiu realizar atendimento odontológico aos grupos prioritários. Os profissionais queixam-se, porém, que estes faltam muito ao atendimento e que há dificuldade de organização desses grupos. Há falta de integração com os outros profissionais da ESF, principalmente com os ACSs, que poderiam auxiliar numa melhor captação desses grupos.

Segundo o Ministério da Saúde 7 , dentre as atribuições do cirurgião-dentista no PSF está o atendimento a grupos prioritários, que são classificados em: crianças, gestantes, diabéticos e hipertensos.

O odontólogo deveria, pois, destinar, no mínimo, dois turnos semanais para o atendimento a esses grupos e se reunir freqüentemente com essa população, aproveitando os mesmos turnos utilizados pelos outros membros das ESFs, compostas pelos médicos, enfermeiros e ACSs, para que estes participem desses encontros.

Há também, por parte da população, uma aceitação da perda dentária. Todavia, ao expor as suas perdas dentárias, o indivíduo expõe também as suas perdas culturais, sociais, econômicas, afetivas, políticas, entre outras. A perda dentária não é natural, pois é produção sociocultural e histórica e tem influências importantes nas subjetividades de quem as sofre (Souza ${ }^{20}$ ).

Merhy22 ressalta que deveria haver uma combinação da melhor forma possível entre eficiência das ações e a produção de resultados centrados nos usuários, isto é, procurar a produção do melhor cuidado em saúde, o cuidado que resulta na cura, promoção e proteção da saúde individual e coletiva. Só que, para isso, há que se conseguir uma combinação ótima entre a capacidade de se produzirem procedimentos e a de ministrar o cuidado.

Concordando com essa idéia, Souza 20 aborda a necessidade de mudanças dos saberes e práticas nos processos de trabalho em saúde; isso exige, porém, novos padrões cognitivos e culturais. A mesma enfatiza que para sairmos da relação entre clínica e saúde coletiva, é necessário que na clínica as ações sejam mais do que apenas o diagnóstico de sinais e sintomas, observando a subjetividade do processo do adoecimento.

As atividades desenvolvidas pela equipe de saúde da família devem ser freqüentemente avaliadas e adaptadas às necessidades da comunidade. É fundamental o acompanhamento dos dados, para posteriormente consolidá-los e servir de base para o planejamento e o redirecionamento das ações (Ministério da Saúde18). 


\section{Considerações finais}

Este estudo teve como objetivos analisar a forma como vem se dando a atuação de cirurgiões-dentistas no PSF do Rio Grande do Norte e mapear as atividades aí desenvolvidas. A investigação realizada possibilitou a identificação de uma série de aspectos que serão aqui retomados.

Observa-se que a precarização das ofertas e condições de trabalho para o CD tem impulsionado este profissional a buscar alternativas de trabalho, mesmo distante dos seus ideais de realização profissional. São raros aqueles que fazem opção pelo trabalho no PSF, por sua filosofia e proposta de atenção à saúde. Quanto ao segundo aspecto, nota-se que a inclusão do $\mathrm{CD}$, tal como ocorre com outros profissionais, é definida por relações pessoais e políticas, o que interfere, certamente, no tipo de trabalho realizado e no comprometimento que esse profissional estabelece com seu trabalho e com a comunidade.

Percebeu-se que os CDs têm perfil profissional voltado para a clínica, aspecto que está relacionado a sua formação acadêmica, mas também devido à própria expectativa da comunidade, bem como da gestão do serviço em priorizar o atendimento clínico. A maioria não possui especialização, e os que têm tal formação concluíram cursos sem nenhuma relação com a saúde pública ou coletiva, demonstrando a falta de preparo acadêmico para uma atuação mais adequada ao PSF.

As atividades básicas que são desenvolvidas no cotidiano, tais como dentística, periodontia básica, cirurgia simples e atividades preventivas e educativas, são realizadas da maneira tradicional, em forma de palestras e aplicação de flúor. Nenhum outro tipo de ação ou recurso foi detectado nas falas dos participantes, demonstrando o limitado arsenal com que trabalham no PSF. Esse perfil clínico preponderante vai de encontro com as características que eles próprios identificaram como sendo imprescindíveis ao trabalho no PSF: ter um conhecimento amplo e multidisciplinar, ter habilidade para atender diferentes tipos de demandas, gostar de trabalhar com comunidades pobres, em zona rural e, principalmente, possuir determinadas características pessoais tais como ser paciente, solidário, corajoso, humano, as quais fazem diferença nesse tipo de trabalho. Não é por acaso que a maioria considera que não atende a esse perfil e, conseqüentemente, enfrenta dificuldades de realização do seu trabalho, especialmente no contato diário com a comunidade. Observa-se que a experiência do PSF não tem conseguido mudar as formas de atuação já estabelecidas, e de criar um outro modo de produzir saúde. O que se vê é a reprodução de práticas tradicionais, fragmentadas e isoladas.

Nos discursos dos participantes, não se observa o cumprimento da carga horária preconizada pelo Ministério da Saúde7, como também a participação em cursos de capacitação promovidos pelo Cefope-RN. Os CDs referem haver participado exclusivamente do Curso Preparatório inicial para o PSF. Isso corrobora a idéia anterior de que tais profissionais passam muito pouco tempo nos seus ambientes de trabalho e que não cumprem a carga horária estabelecida. Aponta, ainda, para a falta de compromisso do profissional com seu trabalho e de controle do gestor sobre isso. A falta de participação em cursos de capacitação está diretamente relacionada ao fato de que muitos desses profissionais encaram sua participação no PSF como uma atividade passageira, a qual não requer investimento do ponto de vista profissional. Os resultados apontam também que há necessidade de motivá-los a refletir e redirecionar as suas práticas, tendo como medida inicial o investimento e estímulo à educação permanente e um monitoramento e avaliação das ações por eles desenvolvidas.

\section{Colaboradores}

YP de Araújo participou de todas as etapas da elaboração do artigo; M Dimenstein participou como orientadora no processo de concepção teórica e na avaliação final do texto. 


\section{Referências}

1. Souza DS et al. A inserção da saúde bucal no Programa de Saúde da Família. Revista Brasileira de Odontologia em Saúde Coletiva 2001; 2(2):7-29.

2. Brasil. Ministério do Planejamento, Orçamento e Gestão. Instituto Brasileiro de Geografia e Estatística. Pesquisa Nacional por População. 2004 [acessado em 2004 out 30]. Disponível em: http:// www.ibge.gov.br.

3. Brasil. Ministério da Saúde. Secretaria de Atenção à Saúde. Departamento da Atenção Básica. Sistema de Informação da Atenção Básica (SIAB): Indicadores 2003. 6a ed. rev. e atual. Brasília: Ministério da Saúde; 2004. (Série G. Estatística e Informação em Saúde).

4. Secretaria de Estado de Saúde Pública. Dados do repasse dos incentivos financeiros PACS/PSF/Saúde Bucal/Similaridade. Rio Grande do Norte: SESP; 2005.

5. Souza TMS. A incorporação da saúde bucal no Programa Saúde da Família no Rio Grande do Norte: investigando a possibilidade de conversão do modelo assistencial [dissertação]. Rio Grande do Norte (RN): Universidade Federal do Rio Grande do Norte; 2005.

6. Werneck AAF. Algumas reflexões sobre cuidado em saúde bucal nos serviços de saúde no Brasil. Belo Horizonte. Mimeo 2003.

7. Brasil. Ministério da Saúde. Portaria no $267 / \mathrm{GM}$ de 6 de março de 2001. Dispõe sobre normas e diretrizes da inclusão da saúde bucal na estratégia do Programa Saúde da Família. Diário Oficial da União. Brasília: Ministério da Saúde; 6 mar. 2001.

8. Brasil. Ministério da Saúde. Secretaria de Atenção à Saúde. Departamento de Atenção Básica. Pesquisa mundial de saúde no Brasil: como os brasileiros auto-avaliam sua saúde? Informe da Atenção Básica no 24; Ano V, Brasília: Ministério da Saúde; 2004.

9. Manfredini MA. PSF: promovendo saúde bucal. Revista Brasileira de Saúde da Família; Edição especial 2004; 5(7):50-4.

10. Pauleto ARC, Pereira MLT, Cyrino EG. Saúde Bucal: uma revisão crítica sobre programações educativas para escolares. Rev S Col 2004; 9(1):121-30.

11. Alves VS. Um modelo de educação em saúde para o Programa Saúde da Família: pela integralidade da atenção e reorientação do modelo assistencial. Revista Interface: Comunicação, Saúde, Educação 2005; 9(16):36-48.

12. Viáfara LE, Brugés CH 1999. Serviços de saúde e comunidades: respondendo ao desafio da formação de novos profissionais. In: Almeida MJ, Feuerwerker LCM, Llanos MA, organizadores. A educação dos profissionais na América Latina: teoria e prática de um movimento de mudança. São Paulo: Hucitec; 1999. p. 181-6.
13. Minayo MCS. O desafio do conhecimento: pesquisa qualitativa em saúde. 2a ed. São Paulo: Hucitec; Rio de Janeiro: Abrasco; 1993.

14. Triviños ANS. Introdução à pesquisa em ciências sociais: a pesquisa qualitativa na educação. São Paulo: Atlas; 1987.

15. Brasil. Ministério da Saúde. Secretaria de Atenção à Saúde. Conselho Nacional de Saúde. Programa Nacional de Doenças Transmissíveis. Diretrizes e normas regulamentadoras de pesquisas envolvendo seres humanos. Brasília: Ministério da Saúde; 1997.

16. Instituto Brasileiro de Estudos e Pesquisas Socioeconômicas - Inbrape. O perfil do cirurgião-dentista no Brasil. Pesquisa realizada para entidades nacionais de odontologia: ABO, ABENO, ACBO, CFO, FIO e FNO, 2003 abr. [acessado em 2005 jan 06]. Disponível em: http://www.cfo.org.br/download/perfil_CD.pdf.

17. Rodrigues MP. O perfil dos profissionais de saúde bucal dos serviços de saúde pública do Rio Grande do Norte. 2001 [acessado em 2005 jan 13]. Disponível em: www.observatorio.nesc.ufrn.br/perfil_t03.htm.

18. Brasil. Ministério da Saúde. Secretaria de Atenção à Saúde. Departamento da Atenção Básica. Avaliação normativa do Programa Saúde da Família no Brasil: monitoramento da implantação e funcionamento das equipes de saúde da família: 2001/2002. Brasília: Ministério da Saúde; 2004 (Série C. Projetos, programas e relatórios).

19. Capistrano Filho D. Inclusão da saúde bucal no Programa de Saúde da Família no Estado do Rio Grande do Sul. Documento. Secretaria da Saúde do Rio Grande do Sul. Departamento de Ações em Saúde. Seção de Saúde Bucal. [acessado em 2004 nov 29]. Disponível em: http://www.saude.rs.gov.br/saude_ bucal/documentos/inclusao_sb_no_psf.pdf.

20. Souza MB. Política estadual de ciência, tecnologia e inovação em saúde. In: Uchoa SAC. (Relatora). Conferência Estadual de Ciência, Tecnologia e Inovação em Saúde, 1a. 2004. Relatório Final. Rio Grande do Norte [acessado em 2005 jan 13]. Disponível em: www.observatorio.nesc.ufrn.br/perfil_t03.htm.

21. Trad LAB, Bastos ACS. O impacto sociocultural do Programa de Saúde da Família (PSF): uma proposta de avaliação. Cad Saúde Pública 1998; 14(2):429-35.

22. Merhy EE. O ato de cuidar: a alma dos serviços de saúde. Texto produzido a partir do texto didático: o ato de cuidar como um dos nós críticos-chave dos serviços de saúde. Curso DMPS/FCM/Unicamp; 1999.

Artigo apresentado em 8/06/2005

Aprovado em 15/07/2005

Versão final apresentada em 22/08/2005 